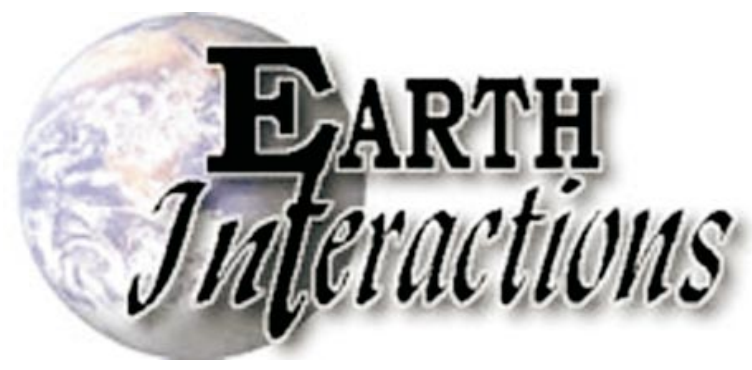

Copyright (c) 1997. Paper 1-003, 7,327 Words, 1 Table, 5 Figures, 4 Animations. http://EarthInteractions.org

\title{
Dynamic interaction between tectonic plates, subducting slabs, and the mantle
}

\section{Shijie Zhong* and Michael Gurnis}

Seismological Laboratory, California Institute of Technology, Pasadena

Received August 1996; accepted 12 February 1997.

\begin{abstract}
Mantle convection models have been formulated to investigate the relation between plate kinematics and mantle dynamics. The cylindrical geometry models incorporate mobile, faulted plate margins, a phase change at $670 \mathrm{~km}$ depth, non-Newtonian rheology, and tectonic plates. Models with a variety of parameters indicate that a relatively stationary trench is more likely to be associated with a subducted slab that penetrates into the lower mantle with a steep dip angle. However, a subducted slab that is deflected above the $670-\mathrm{km}$ phase change with a shallow dip is more likely to be associated with a margin that has undergone rapid retrograde trench migration. This relation between slab morphology and plate kinematics is consistent with seismic tomography and plate reconstruction of western Pacific subduction zones. The efficiency of slab penetration through the $670-\mathrm{km}$ phase change is controlled by both the buoyancy of the subducting plate and the mobility of the overriding plate. While older subducting plates have a greater propensity for slab penetration, trench mobility reduces the propensity for slab penetration. Smaller overriding plates have a greater mobility. When subducted slabs approach the bottom thermal boundary layer, hot fluid is pushed aside, and plumes form on the periphery of slab accumulations. There are sharp temperature contrasts between the subducted slab and the thermal boundary layer
\end{abstract}

* Corresponding author address: Shijie Zhong, Seismological Laboratory, California Institute of Technology, Pasadena, CA 91125.

E-mail address: zhong@gps.caltech.edu 
at the core mantle boundary (CMB). Old subducted slabs and a thermal boundary layer lead to large-scale lateral structure near the CMB.

KEYWORDS: Dynamics of lithosphere and mantle-General; Dynamics, convection currents, and mantle plumes; Plate motions-General; RheologyGeneral

\section{Introduction}

Plate tectonics is the surface manifestation of mantle convection. Previous numerical studies have shown that plate kinematics have a fundamental influence on mantle flow and thermal structure (e.g., Hager and O'Connell, 1981; Davies, 1988; Gable et al., 1991; Zhong and Gurnis, 1994a; King and Ito, 1995; Bunge and Richards, 1996). While these studies clearly demonstrate the influence of plates on mantle convection by imposing plate motion and/or plate geometry in the models, they only provide a limited understanding of plate dynamics. Plate geometry and plate motion have varied in the geologic past and this indicates that plate geometry and motion dynamically respond to time-dependent mantle convection. The change in plate geometry must occur through variations in the geometry of plate margins. Therefore it is essential to formulate models of mantle convection that include plates with dynamically evolving plate margins.

Initial efforts to formulate models with dynamically evolving margins were made by Gurnis and Hager (Gurnis and Hager, 1988), who simulated plates of variable size through a weak zone formulation; one weak zone was attached to an overriding plate that was fixed as a reference frame, while the other weak zone was used to simulate a ridge that moves with the mean velocity of the two adjacent oceanic plates. In two- dimensional models with periodic boundary conditions, Gurnis and Hager (Gurnis and Hager, 1988) found that the dip of slabs was steeper following the initiation of subduction and later became shallower. At $670 \mathrm{~km}$ depth, their models did not incorporate an endothermic phase change and simulated the boundary with just an increase in viscosity with depth. To overcome these limitations, we have incorporated plate margins into viscous flow more realistically with tectonic faults (Zhong and Gurnis, 1994b, Zhong and Gurnis, 1995a). Two-dimensional models of a subduction zone with dipping faults indicate that oceanic trenches originate from the dynamic compensation of negatively buoyant subducted slabs. Trench depth is controlled by the dip angle of faults and lithospheric age prior to subduction, consistent with observations of trench depth (Zhong and Gurnis, 1994b). Recently, faults with different strikes and dips have been incorporated into three-dimensional models that are capable of reproducing "plate-like" surface motion including little internal strain within a plate, significant strike-slip motion, oblique subduction, oceanic trench topography, and long-wavelength geoid highs over slabs (Zhong and Gurnis, 1996). In time-dependent dynamic models within a two-dimensional cylindrical geometry, we have shown that faulted plate margins migrate under the influence of mantle buoyancy, leading to variations in plate size; the migration of plate margins determines the dynamics of subducted slabs including slab penetration through the $670-\mathrm{km}$ dis- 
continuity (Zhong and Gurnis, 1995a). The influence of trench migration on the dynamics of subducted slabs is consistent with a recent study by Christensen (Christensen, 1996) in which trench migration is kinematically imposed.

In this paper, we continue to explore the dynamics of multiple plate margins and their influence on subducted slabs. We consider the role of periodic boundary conditions and a hot bottom thermal boundary layer, which were not considered previously. Our models with periodic boundary conditions confirm our previous results and indicate that converging margins migrate rapidly oceanward when the slabs are deflected above the $670-\mathrm{km}$ phase change but converging margins tend to be more stationary after subducted slabs penetrate into the lower mantle. We find that the size of the overriding plate influences its mobility and consequently the mobility of converging margins. In addition to the buoyancy of the subducting plate, we find that the size of the overriding plate also influences slab penetration through the $670-\mathrm{km}$ phase change. Upon reaching the bottom thermal boundary layer, subducted slabs spread out over the core mantle boundary (CMB) and push aside hot thermal boundary layer fluid. This causes the thermal boundary layers to become unstable; as a result, plumes form in the lower mantle within the thermal boundary layer. Rising plumes appear to penetrate more easily the endothermic phase change at $670 \mathrm{~km}$, compared with slabs, and this confirms the results from models of convection with stationary plate margins (Davies, 1995).

\section{Description of models and numerical methods}

The governing equations for mantle convection are derived from the conservation of mass, momentum, and energy. With the Boussinesq approximation, the momentum, continuity, and energy equations are

$$
\begin{aligned}
\sigma_{i j, j}+f_{i} & =0, \\
\mathrm{u}_{i, i} & =0, \\
\frac{T}{t}+u_{i} T_{i} & =\kappa T_{i i}+H
\end{aligned}
$$

respectively, where $u_{i}, f_{i}$, and $\sigma_{i j}$ are the flow velocity, the body force, and the stress tensor, respectively; $T$ is the temperature; $t$ is the time; $\kappa$ is the thermal diffusivity; $H$ is the heat source; the differential operators are those appropriate for a cylindrical geometry. The body force vector includes buoyancy force due to temperature variations and phase changes, and stress tensor $\sigma_{i j}$ is related to strain rate tensor, $e_{i j}=u_{i, j}+u_{j, i}$ with $\sigma_{i j}=-P \delta_{i j}+2 \mu_{\mathrm{eff}} e_{i j}$, where $P$ is the pressure, $\delta_{i j}$ is the unit tensor, $\mu_{\text {eff }}$ is the effective dynamic viscosity and can be expressed as

$$
\mu_{\text {eff }}=\frac{2 \mu}{1+(2 \mu e / \tau)_{t}^{(n-1) / n}}
$$

where $n$ is the exponent and for Newtonian rheology equals $1, e$ is the second invariant of the strain rate tensor; $\tau_{t}$ is the transition stress, $\mu$ is assumed to be temperature-dependent, 


$$
\mu=\mu_{0} \exp \left(\frac{c_{1}}{T+c_{2}}-\frac{c_{1}}{1+c_{2}}\right)
$$

where $c_{1}$ and $c_{2}$ are constants and $\mu_{0}$ is the viscosity at nondimensional temperature $T=1$.

Three formulations have been used to incorporate plates into mantle convection models: material property, thin plate, and force balance methods (e.g., King et al., 1992). In the material property method, weak zones are assigned to plate margins, while plate interiors are assigned a viscosity much higher than the mantle. The weak zones are intended to mimic the stress weakening of lithosphere near plate margins. Models that use the material property method can reproduce platelike surface motion (e.g., Gurnis, 1989; Jacoby and Schemling, 1982), but special kinematic constraints are needed to advect plate margins (e.g., Gurnis and Hager, 1988; Puster et al., 1995). In thin plate models, plates, coupled into the underlying mantle flow through boundary conditions, are modeled with a thin plate approximation (e.g., Weinstein and Olson, 1992). Such a formulation has been applied to both two-dimensional Cartesian and cylindrical geometries (Weinstein and Olson, 1992; Weinstein, 1996). Although a highly non-Newtonian rheology (i.e., a power law rheology with an exponent as high as 20) is used for plates, surface motion still displays significant deformation over broad regions (Weinstein, 1996). In the force balance method, each plate, with a prescribed geometry, is assumed to have a constant velocity (or angular velocity); the velocity is determined by balancing the force (or torque) at the base of each plate (e.g., Ricard and Vingy, 1989; Gable et al., 1991). This later formulation has been incorporated into three- dimensional convection models in order to study the partitioning between poloidal and toroidal velocity components with a fixed plate geometry (Gable et al., 1991).

The two-dimensional models are in a full cylinder with periodic boundary conditions and represent a significant extension of our previous models within a half cylinder with reflecting boundary conditions (Zhong and Gurnis, 1995a); reflecting boundary conditions may influence the dynamics by enforcing the symmetry on the sidewalls (Gurnis and Hager, 1988). The models include continental and oceanic plates that are separated by thrust faults and weak spreading centers at converging and diverging margins, respectively (Figure 1). A finite element method is used to solve convection models with a fault (Zhong and Gurnis, 1994b). The mobility of the fault emerges from a mixed Eulerian and Lagrangian formulation (Zhong and Gurnis, 1995b). Converging plate margins are represented with faults that extend down to the bottom of a plate with an initial dip angle of $30^{\circ}$. Overriding faults are continents with a constant horizontal length, while the remaining surface is oceanic lithosphere (Figure 1). The models include an endothermic phase change at $670 \mathrm{~km}$ depth (Table 1). Initially, the fluid interior is isothermal $\left(1600^{\circ} \mathrm{C}\right)$ and two cooling oceanic plates are included with zero age at $\theta=0$ (Figure 1). Within the two overriding continents, there is no horizontal gradient in temperature. At the diverging margin of the overriding continents (that is, at $\theta=\pi$ in Figure 1), a high temperature is set initially to mimic continental rifting. The two continents initially cover the whole region from the converging margins to the weak margin at $\theta=\pi$ (Figure 1). 


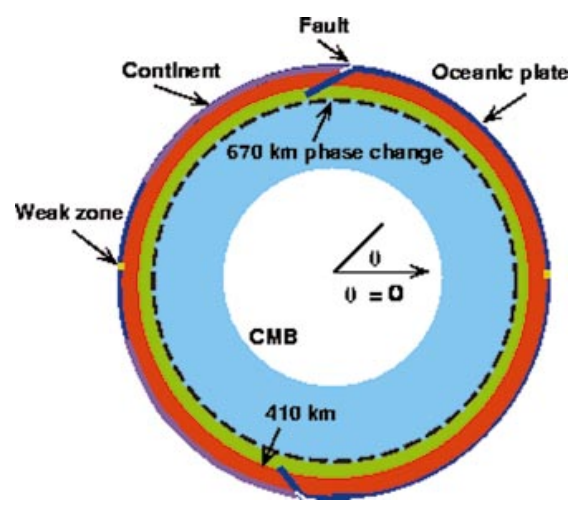

Figure 1. Model setup for cases within a full cyinder.

The continents, oceanic plates, and mantle are composed of different rheologies. Regions below $410 \mathrm{~km}$ in depth are assumed to undergo Newtonian flow, while the shallower regions excluding continents are assumed to undergo nonNewtonian flow (e.g., Karato and Wu, 1993; van den Berg et al., 1993). Viscosity in any region can be expressed with (4) and (5) with a set of constants $\left(\mu_{0}, \mathrm{c}_{1}\right.$, $\mathrm{c}_{2}, n, \tau_{\mathrm{t}}$ ). These constants for the lower mantle, the transition zone, the upper mantle, and lithosphere are chosen such that the resulting average effective viscosity (Table 1) is similar to that inferred from geoid studies, in which the viscosity is high in the lower mantle but low in the transition zone (Hager and Clayton, 1989; King and Masters, 1992). This viscosity structure is potentially consistent with recent glacial rebound studies (Forte and Mitrovica, 1996). The nonsubducting continents are assumed to be Newtonian with a constant high viscosity (Table 1). At divergent margins, a smaller $\mu_{0}$ or $\tau_{\mathrm{t}}$ was used to account for the weakening by partial melting.

The boundary conditions are isothermal and free slip on both the bottom and top boundaries. The zones occupied by continents are updated under the assumption that the length of the continents is constant; the region vacated by continents is occupied by new ocean floor having a temperature- and strain ratedependent rheology identical to that of subducting plates. While migration of faulted converging margins is dictated by the normal velocities on the faults, the spreading centers migrate by assuming symmetric spreading (e.g., Gurnis and Hager, 1988). Therefore all converging and diverging margins are capable of dynamically moving with respect to each other. The assumption of symmetric spreading is a "rule-based" constraint in contrast with motion of faulted converging margins that is dynamically self-consistent. A mesh with 600 by 70 bilinear elements was used for all the cases, and the mesh was refined near the fault, phase change, and plates.

\section{Results}

Our models of mantle convection with plates and faulted plate margins show that the migration of plate margins influences the dynamics of plates and subducted 
slabs. The models indicate that converging margins migrate rapidly oceanward when the slabs are deflected above the $670-\mathrm{km}$ phase change, while converging margins tend to become stationary following the penetration of subducted slabs into the lower mantle. In addition to oceanic plate buoyancy, overriding plate size has a significant influence on the mobility of overriding plates and thus on slab penetration through a phase change at $670 \mathrm{~km}$ depth. For comparison, we will first show a case with reflecting boundary conditions (i.e., within the domain of a half cylinder). We will then present three cases with different sized overriding continents and bottom thermal boundary layers of different strengths.

\subsection{A case with reflecting boundary conditions}

For reference and comparison with other more complex cases, we have a case 1 in which flow is confined to a half cylinder using reflecting boundary conditions at $\theta=0$ and $\theta=\pi$ (i.e., the flow within the other half cylinder is symmetric). We will present the complete time history of the thermal structure of the fluid interior, plate surface motion, and plate geometry as Figure 3. This case was described without the use of animation in Zhong and Gurnis (Zhong and Gurnis, 1995a). This model shows surface heat flux and dynamic topography consistent with observations (Zhong and Gurnis, 1995a), but here we will concentrate on the time evolution of thermal structure and resulting plate kinematics. In the animation, model time is shown in the top right corner, allowing one to make a correspondence between the times mentioned in text and those on the time history plots.

The buoyancy of the initial cooling lithosphere and the high temperature at the continental margin $(\theta=\pi)$ causes subduction of the oceanic plate and motion of continental plate shortly after the model starts. Accompanying the continental motion, the faulted converging margin moves oceanward (i.e., trench migration) and the overriding continental plate grows in size with new ocean floor added at the spreading center. The fault position and spreading center position are directly below the jumps in surface horizontal velocity seen in the animation as thin green lines. When the newly descending slab encounters the phase change at $670 \mathrm{~km}$ at 55 m.y., plate motion is slightly retarded (Figure 2a). Initially, the slab cannot penetrate the phase change, and it bends in the transition zone slightly (Figure 3, $50-117$ m.y.). During this period the subducting and overriding plates converge with a relatively constant velocity (Figure $2 \mathrm{a}$ ), and the overriding plate increases its size at the expense of the subducting plate. By $\sim 200 \mathrm{~m}$.y. the length of the overriding plate has increased by more than $2000 \mathrm{~km}$ (Figure 2b). The slab sinks into the lower mantle, apparently after sufficient amount of cold material has built up above the phase change (e.g., Tackley et al., 1993). As the slab sinks into the lower mantle ( $\sim 200$ m.y.), the velocity of the subducting plate increases rapidly, while the velocity of the overriding plate decreases substantially (Figure 2a and Figure 3). The decrease in overriding plate velocity (i.e., reduced trench migration rate) slows the growth of the overriding plate (Figure 2a). As the slab reaches the bottom boundary ( $226 \mathrm{~m} . \mathrm{y}$.$) , the velocity of the subducting plate gradually$ decreases to a relatively constant velocity of $\sim 4.0 \mathrm{~cm} / \mathrm{y}$ (Figure $2 \mathrm{a}$ ). After the slab penetrates into the lower mantle, it penetrates steadily, and the final configuration of slab and plates is quite stable (Figure 3). 

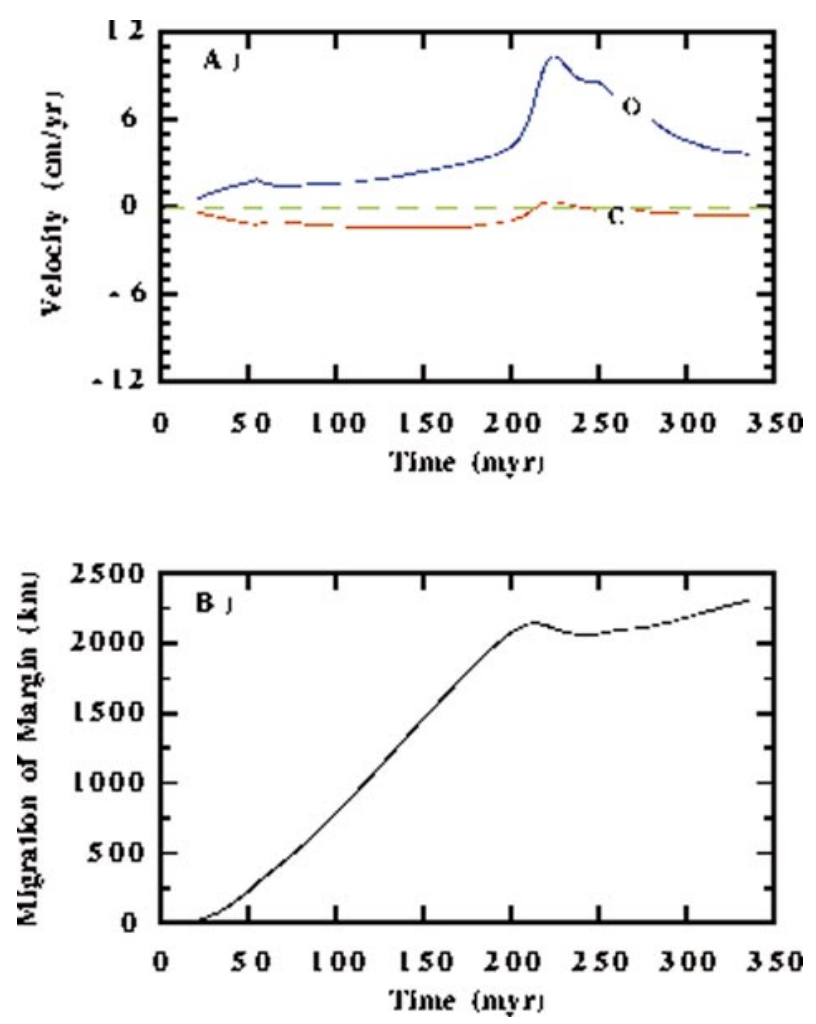

Figure 2. Time history of (a) plate velocities and (b) trench migration for case 1. Symbols $O$ and $C$ in Figure $2 a$ indicate the velocities of oceanic and continental plates, respectively. The green dashed line in Figure 2a indicates zero velocity.

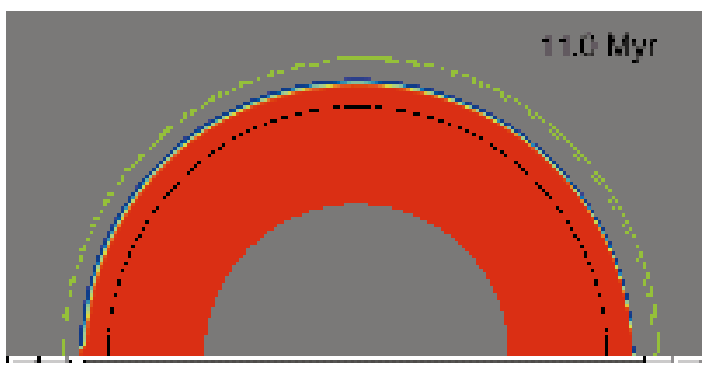

Movie 1. A Quick Time animation of thermal structure and surface plate velocity (solid green line) for case 1 with the times marked at the top right corner. The dashed green line indicates the zero velocity. The velocities are uniformly reduced by a factor of two after $213 \mathrm{~m}$.y. The black line indicates the $670-\mathrm{km}$ phase change. See Figure 1 for geometrical coordinates.

See the online version of this paper to view animation. 
Surface velocities demonstrate that plate-like behavior (that is, there is only significant strain near plate margins) is achieved for both overriding and subducting plates (green lines in Movie 1). The overriding plate consists of both a continental and an oceanic component, but the piecewise continuous surface velocity indicates that they form a single coherent plate (Movie 1). During the early stages of subduction the slab is deflected above the $670-\mathrm{km}$ phase change with a shallow dip angle, while the slab also can extend landward by more than 1000 $\mathrm{km}$. After the slab penetrates into the lower mantle, the slab has a steep dip (Movie 1). When the slab is deflected above the 670-km phase change, the trench tends to migrate at a larger rate. However, when the slab penetrates into the lower mantle, the trench is immobile.

\subsection{Periodic boundary conditions}

The competing influence of lithosphere buoyancy and overriding plate size on plate kinematics and slab penetration through the $670-\mathrm{km}$ phase change is explored with two cases in a full cylinder. In case 2, the length of the overriding continent and the initial length of the oceanic plate in the upper hemisphere are the same as those in the lower hemisphere, respectively (Figure 1) and are also the same as those in case 1 . However, the oceanic plate in the lower hemisphere is initially $20 \%$ older near the dipping fault (i.e., more negatively buoyant) than that within the oceanic plate in the upper hemisphere. An initially older oceanic plate is accomplished by decreasing the oceanic plate spreading velocity used to determine the initial temperature field. This difference in buoyancy introduces an asymmetry in mantle flow between the upper and lower hemispheres. Since the asymmetry is only slight, the time evolution is similar to that in case 1 and the model was run only for $\sim 200$ m.y.

After only a short integration in time we observe the subduction of oceanic plates near faults and motion of overriding plates in both hemispheres, along with trench migration and growth in the size of overriding continental plates (Movie 2 ; Figure 3). Since the oceanic plate in the lower hemisphere has a greater buoyancy, it moves faster, compared with the oceanic plate in the upper hemisphere (Figure 3). This results in a migration of the spreading center separating the two oceanic plates toward the lower hemisphere at a rate half the differential motion between these two plates (Movie 2 and Figure 3). The spreading center velocity enforces symmetric spreading. Before 140 m.y. the overriding continental plate in the lower hemisphere has a larger velocity than that in the upper hemisphere, while after $140 \mathrm{~m} . \mathrm{y}$. the overriding continental plate in the lower hemisphere has a smaller velocity than that in the upper hemisphere (Figure 4 and Figure 3 ). The difference in continental plate velocities between the upper and lower hemisphere is less than the difference of subducting plate velocities; therefore there is less migration of the spreading center between the two continents (Figure 3). The migration of the two converging margins is much larger than that of the spreading centers (Figure $3 b$ ). As converging margins migrate, the cold slabs are deflected above the $670-\mathrm{km}$ phase change with shallow dips, as found in case 1 . By $\sim 170$ m.y. the slab in the lower hemisphere starts to penetrate into the lower mantle, along with an increase in velocity of the subducting plate and a decrease in 


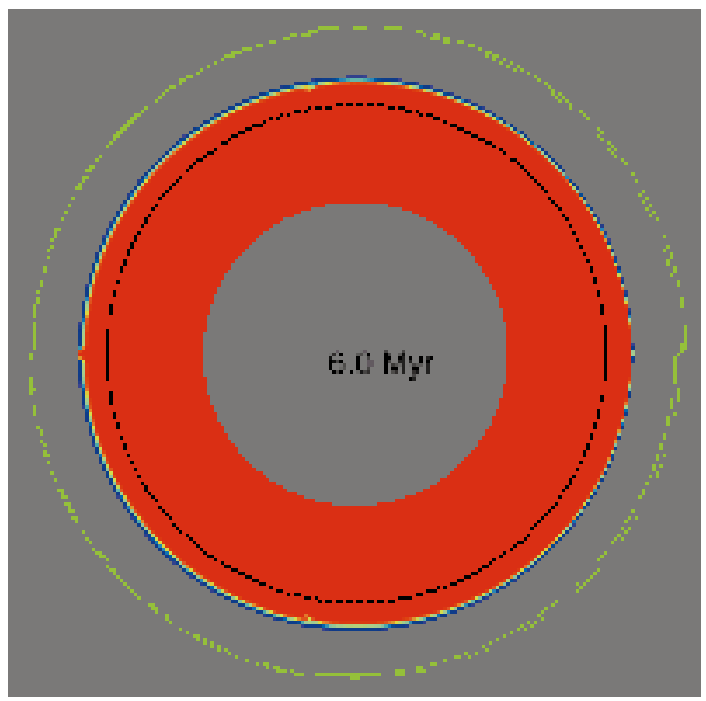

Movie 2. A Quick Time animation of thermal structure and surface plate velocity (solid green line) for case 2 with the times marked at the center of the cylinder. The velocities are uniformly reduced by a factor of 2 after 136 m.y. See Movie 1 for other information.

See the online version of this paper to view animation.

velocity of the overriding plate (i.e., decreasing rate of trench migration) in the lower hemisphere (Movie 2 and Figure 3). When the slab penetrates the $670 \mathrm{~km}$ depth with a steep dip, the migration rate of the spreading center between the oceanic plates increases rapidly because of the increasing differential velocity between the two oceanic plates (Movie 2 and Figure 3). The slab in the upper hemisphere only starts to penetrate the $670-\mathrm{km}$ phase change after $200 \mathrm{~m}$.y. when overriding plate velocity is reduced rapidly (Figure 4 and Figure 3). Case 2 suggests that older plates with larger negative buoyancy force penetrate easier into the lower mantle, consistent with earlier work (Zhong and Gurnis, 1994a).

In order to study the influence of overriding plate size we have reduced the size of the overriding continent by $2000 \mathrm{~km}$ in the lower hemisphere in case 3 . Since we assume that initial lithospheric age increases at the same rate for both oceanic plates, the oceanic plate in the lower hemisphere is older (i.e., more negatively buoyant) at the fault. The asymmetry in mantle flow between the upper and lower hemispheres results from the differences in both buoyancy and continent size.

The general characteristics of the results from case 3 are similar to those in the previous two cases (Movie 3). Unexpectedly, the slab attached to the younger oceanic plate in the upper hemisphere penetrates through the $670-\mathrm{km}$ endothermic phase change and into the lower mantle earlier than the one in the lower hemisphere (Movie 3). Before 150 m.y., oceanic plates in both hemispheres move at similar velocities (Movie 3 and Figure 4a). Although the oceanic plate in the 

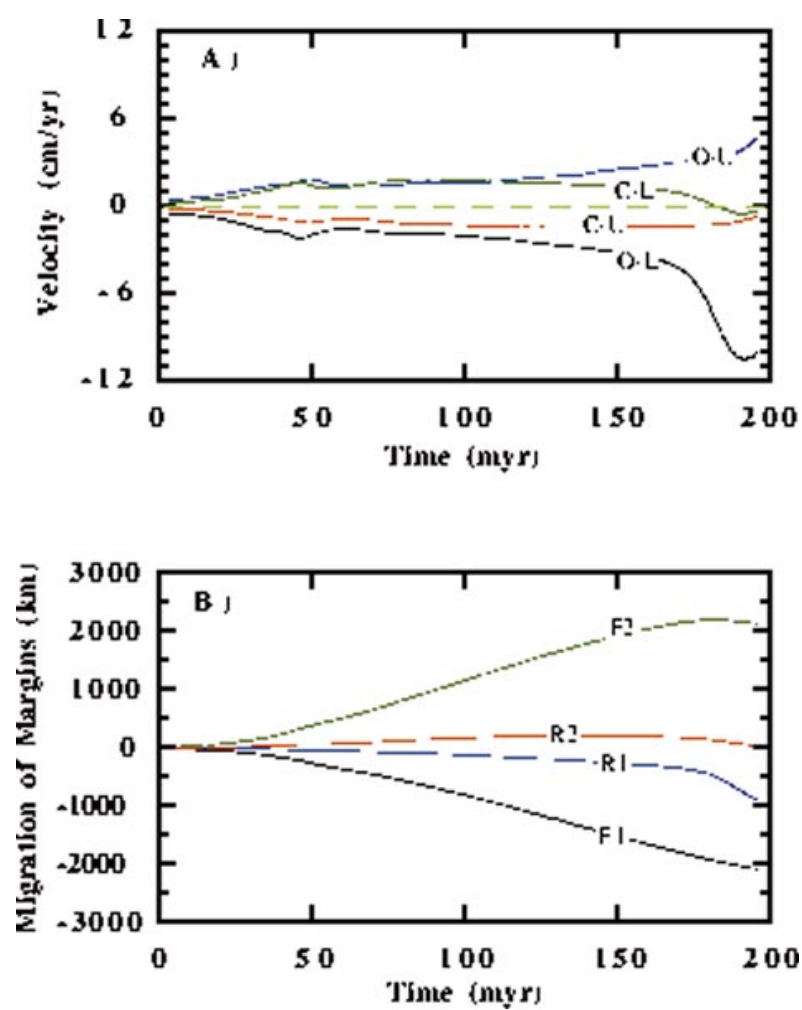

Figure 3. Time history of (a) plate velocities and migration of (b) plate margins for case 2. Symbols O-U, C-U, O-L, and C-L in A indicate the velocities of oceanic and continental plates in the upper and lower hemispheres, respectively. In Figure 3b, symbols $\mathrm{F} 1$ and $\mathrm{F} 2$ dictate the migration of faulted converging margins in the upper and lower hemispheres, respectively, while symbols R1 and R2 stand for the spreading centers bounded by two oceanic plates and two continental plates, respectively. The green dashed line in Figure $3 a$ indicates zero velocity.

lower hemisphere has a larger negative buoyancy, it also has a larger size. By $\sim 150$ m.y. the velocity of oceanic plate in the upper hemisphere becomes larger than that in the lower hemisphere (Figure 4). The overriding plate in the lower hemisphere has a larger velocity than that in the upper hemisphere with the largest difference in velocity occurring within the first 120 m.y. (Figure 4). The overriding plate in the lower hemisphere is more mobile because it is smaller. The smaller overriding plate leads to more trench rollback, and we suspect that this is the cause of the delayed penetration of the slab into the lower mantle.

The slab in the upper hemisphere sinks into the lower mantle at $\sim 180$ m.y. (Movie 3), after which the velocity of overriding continental plate (i.e., trench migration velocity) in the upper hemisphere decreases rapidly (Figure 4). The slab in the lower hemisphere penetrates into the lower mantle at $\sim 200$ m.y. (Movie 3 and Figure 4). By the time that slabs start sinking into the lower mantle 


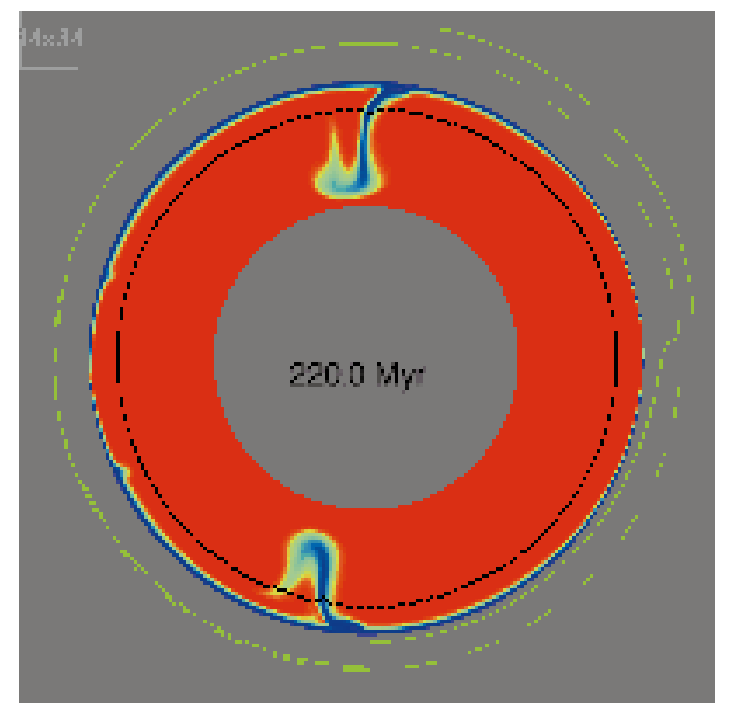

Movie 3. A Quick Time animation of thermal structure and surface plate velocity (solid green line) for case 3 . The velocities are uniformly reduced by a factor of 2 after $197 \mathrm{~m}$.y. See Movie 1 for other information.

See the online version of this paper to view animation.

the two converging plate margins have migrated from their original positions by $\sim 2000$ and $2700 \mathrm{~km}$ in the upper and lower hemispheres, respectively (Figure 4). Since the overriding continental plate has a larger velocity in the lower hemisphere than that in the upper hemisphere, the spreading center separating the two overriding plates has migrated toward the lower hemisphere for $\sim 300 \mathrm{~km}$ before the slabs sink into the lower mantle (Figure 4). The spreading center separating the two oceanic plates has only a significant motion toward the upper hemisphere after the slab in the upper hemisphere starts to sink into the lower mantle (Movie 3 and Figure 4).

These three cases do not include a thermal boundary layer near the CMB. Bottom thermal boundary layers may develop in response to heat flux from core to mantle. Some studies (Davies and Richards, 1992; Sleep, 1990) have argued that this heat flux may amount to $10-15 \%$ of the Earth's heat budget. We investigate the interaction of slabs with a bottom thermal boundary layer and its influence on plate kinematics. Case 4 includes a bottom thermal boundary layer in its initial temperature field but otherwise is identical to case 3 . There is no initial horizontal gradient in temperature within the thermal boundary layer, and the temperature increases by $800^{\circ} \mathrm{C}$ across the lower $250 \mathrm{~km}$ of the mantle.

The time history of plate motion for case 4 (Figure 5) indicates that the bottom thermal boundary layers do not influence significantly the general characteristics of plate kinematics except the magnitude of plate motion. In the initial stage (e.g., first 50 m.y.) the bottom boundary layers are stable, and no significant change occurs within the thermal boundary layers (Movie 4). When slabs accu- 

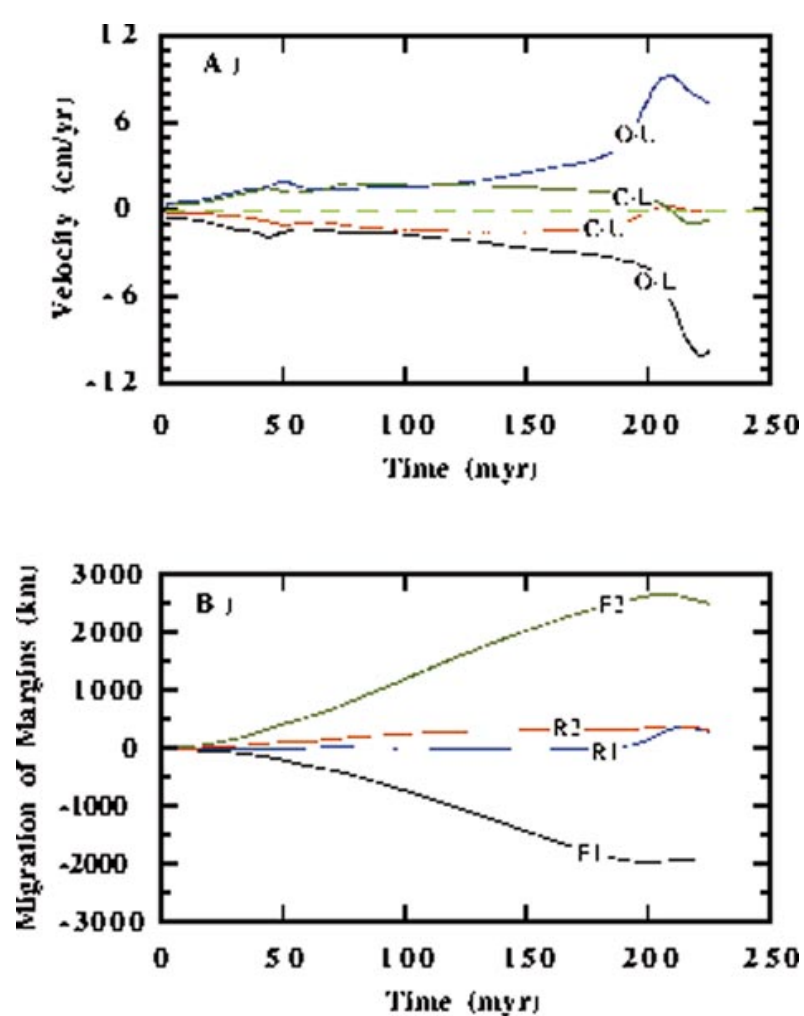

Figure 4. Time history of (a) plate velocities and migration of (b) plate margins for case 3. See Figure 3 for symbol convention.

mulate above the $670-\mathrm{km}$ phase change, we observe that the bottom thermal boundary layers appreciably thin under the slabs and thicken beneath the spreading centers. The thickening thermal boundary layer forms plume-like structures (Movie 4). This thermal structure results from the global flow field: the upwelling flows under the spreading centers form plumes and the downwelling flows under the slabs thin the thermal boundary layers beneath. When slabs sink into the lower mantle, they enhance the flow in the lower mantle, which destablizes the bottom thermal boundary layers and causes the plumes under the spreading centers to grow rapidly. It should be pointed out that the rapid growing plumes under the spreading centers may be partly due to the two-dimensional effects in our models. As the sinking slabs approach the $\mathrm{CMB}$, hot fluid underneath the slabs is pushed aside, leading to the formation of additional plumes on the CMB (Movie 4). After the slabs reach the CMB they spread over the CMB. This enhances plumes on the periphery of old slabs, causing strong lateral variations in temperature and a distinct large-scale thermal structure above the CMB (Movie 4). These results of the interaction between cold slabs and mantle plumes at the CMB are similar to those reported by Yuen et al. (Yuen et al., 1994).

Other interesting features include the penetration of plumes into the upper mantle and the destablization of continental plates at passive margins near the 

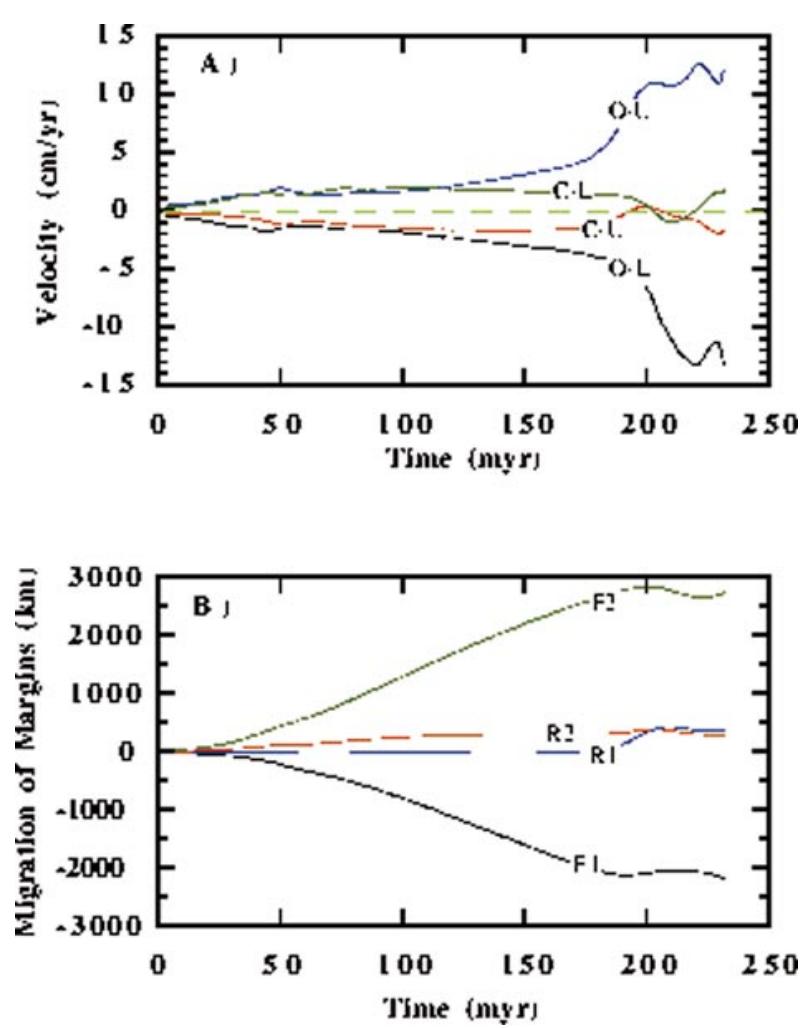

Figure 5. Time history of (a) plate velocities and migration of (b) plate margins for case 4. See Figure 3 for symbol convention.

end of the model run (Movie 4). The 670-km phase change does not significantly resist the penetration of the plume near $\theta=0$ into the upper mantle as it does for the slabs when they penetrate through the phase change. The increasingly large buoyancy associated with the oceanic component of overriding plates causes compressional strain to build up within the oceanic lithosphere at the continental margins, and this eventually results in new subduction at the margins (Movie 4). We did not integrate this system further in time, because this would have required the initiation of new faults. Fault initiation is left for future investigation.

\section{Discussion}

These results suggest that there may be an intimate relationship between slab penetration, slab dip, and migration of converging margins. On the one hand, a subducted slab with a steep dip angle is more likely to be associated with a relatively stationary trench, and the subducted slab is more likely to extend into the lower mantle. On the other hand, a subducted slab with a shallow dip is more likely to be associated with a rapid retrograde trench migration, and the subducted slab is less likely to have penetrated into the lower mantle. The same relationship 


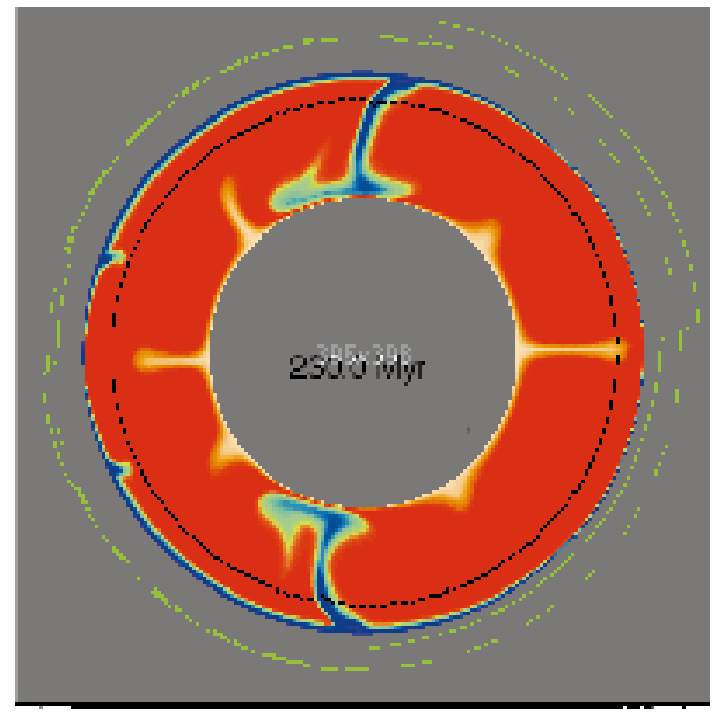

Movie 4. A Quick Time animation of thermal structure and surface plate velocity (solid green line) for case 4 . The velocities are uniformly reduced by a factor of 2 after 187 m.y. See Movie 1 for other information.

See the online version of this paper to view animation.

was previously suggested with half cylinder models (Zhong and Gurnis, 1995a). Laboratory studies also suggested that subducted slabs with shallower dips have a smaller propensity of penetration into a lower layer with an increased density and viscosity (Kincaid and Olson, 1987). The relationship between slab morphology and mobility of converging margins from our models is similar to the correspondence between slab morphology revealed through seismic tomography and plate reconstructions. Seismic tomography of western Pacific subduction zones indicate that the steeply dipping Mariana and Southern Tonga slabs may extend into the lower mantle, whereas the more shallowly dipping Izu-Bonin, central Japan, and Northern Tonga slabs may be deflected above the 670-km discontinuity (van der Hilst and Seno, 1993; van der Hilst, 1995). Plate reconstruction suggests that in the last 45 m.y. the Mariana trench has not had significant retrograde migration whereas the Izu-Bonin trench and Japan trench has migrated oceanward significantly (Seno and Maruyama, 1984). The Tonga trench has experienced a larger amount of trench migration in its northern segment compared with its southern segment in the past 40 m.y. (Walcott, 1987).

Our models suggest that the propensity of slab penetration at the $670-\mathrm{km}$ phase change depends on both the buoyancy of subducting plates and the mobility of overriding plates. While older plates in general have a greater propensity to penetrate through the 670-km phase change (e.g., case 2 and Zhong and Gurnis, 1994a), overriding plates with a great mobility reduce the propensity of slab penetration, as demonstrated in case 3 . This result may be important in understanding the fate of slabs at $670 \mathrm{~km}$ depth. This probably explains the variability 
in seismically derived slab structure at the 670-km discontinuity in western Pacific subduction zones that have similar lithospheric ages of subducting plates. In reality, the mobility of overriding plates (or overriding slivers) could be influenced by many factors including the size of overriding plates and the existence of back arc spreading. Therefore subducted slabs with similar ages may have very different propensity of slab penetration into the $670-\mathrm{km}$ discontinuity if the overriding plates have different conditions. This is approximately what studies of seismic tomography and plate reconstruction suggest (e.g., van der Hilst and Seno, 1993). Admittedly, different endothermic phase change parameters and rheology will have influences on the dynamics of subducted slabs (e.g., Christensen and Yuen, 1984; Zhong and Gurnis, 1994a, 1995a; King and Ito, 1995), and these influences are not considered in this paper. However, we believe that our general conclusions regarding the influences of trench migration on slab penetration do not significantly depend on these model parameters.

The thermal structure of subducted slabs and the bottom thermal boundary layers from our models can be comparable with seismic observations. Seismic tomography studies suggest that subducted slabs may be deflected by the $670-\mathrm{km}$ discontinuity with a shallow dip, like under central Japan (Zhou et al., 1990; Fukao et al., 1992), or penetrate into the lower mantle with a steep dip, as beneath the Mariana trench and Tonga (van der Hilst et al., 1991). Grand (Grand, 1994) has shown that the subducted slab under western North America can be clearly traced to the core-mantle boundary, with a structure similar to that seen in our models. The cold slabs spreading over the CMB push aside the thermal boundary layer fluid, leading to formation of plumes on the periphery of slabs on the CMB (e.g., case 4 and Yuen et al., 1994). The cold slabs and their surrounding thermal boundary layers may produce the large-scale structure in the lowermost mantle as observed by Wysession et al. (Wysession et al., 1994) and Grand (Grand, 1994). A sharp temperature contrast between the cold slabs and the thermal boundary layers persists after the cold slabs reach the boundary layers for tens of millions of years (e.g., case 4). This sharp temperature contrast may be related to the observed seismic velocity anomalies near the CMB by Garnero and Helmberger (Garnero and Helmberger, 1996) and Ding and Helmberger (Ding and Helmberger, 1997). It should be pointed out that the temperature contrast would be reduced as the cold fluid travels away from the slabs over the CMB and is heated by the thermal boundary layers. However, the large-scale thermal structure on the CMB can be maintained for a much longer time, as long as the subduction remains a continuous process and brings additional cold fluid to the CMB.

\section{Conclusions}

We have formulated mantle convection models that incorporate non-Newtonian rheology, tectonic plates, and faulted plate margins. These models allow us to relate plate kinematics to the internal dynamics of the mantle. Our models with different model parameters indicate that converging margins migrate rapidly oceanward when slabs lay above the $670-\mathrm{km}$ phase change, but converging margins tend to be more stationary after slabs penetrate into the lower mantle, consistent with seismic tomography and plate reconstruction in western Pacific sub- 
duction zones (van der Hilst and Seno, 1993) and confirms our previous inferences (Zhong and Gurnis, 1995a). We find that the ability of slabs to penetrate through the $670-\mathrm{km}$ phase change is controlled by both the buoyancy of subducting plates and the mobility of overriding plates (i.e., trenches). While older subducting plates have a greater propensity of slab penetration, which is consistent with our previous studies (Zhong and Gurnis, 1994a), mobile trenches reduce the propensity of slab penetration, consistent with laboratory and numerical studies (Kincaid and Olson, 1987; Zhong and Gurnis, 1995a). The mobility of overriding plates is influenced by the size of overriding plates and other factors including back arc spreading. Overriding plates with a smaller size appear to have greater mobility. When reaching the bottom thermal boundary layer, subducted slabs spread over the CMB and push aside the hot material, producing thermal plumes that rise from the thermal boundary layer. The spreading cold fluids and the thermal boundary layers form a large-scale structure near the CMB; there can be a sharp temperature contrast between the cold fluids and the thermal boundary layers. This structure may be partially responsible for the seismic observations on the CMB.

Acknowledgments. Funded by the David and Lucile Packard Foundation and NSF grant EAR-9496185. Thanks to S. King and an anonymous reviewer for their reviews. This is contribution 5781 of the Division of Geological and Planetary Sciences of the California Institute of Technology.

\section{References}

Bunge, H.-P. and M. A. Richards. 1996. The origin of large-scale structure in mantle convectionEffects of plate motions and viscosity stratification. Geophys. Res. Lett, 23, 2987-2990.

Christensen, U. 1996. The influence of trench migration on slab penetration into the lower mantle. Earth Planet. Sci. Lett, 140, 27-40.

Christensen, U. and D. A. Yuen. 1984. The interaction of a subducting lithospheric slab with a chemical or phase boundary. J. Geophys. Res, 89, 4389-4402.

Davies, G. F. 1988. Role of the lithosphere in mantle convection. J. Geophys. Res, 93, 10-466.

Davies, G. F. 1995. Penetration of plates and plumes through the mantle transition zone. Earth Planet. Sci. Lett, 133, 507-516.

Davies, G. F. and M. A. Richards. 1992. Mantle convection. J. Geol, 100, 151-206.

Ding, X.-M. and D. V. Helmberger. 1997. Modeling D“ structure beneath Central America with broadband seismic data. Phys. Earth Planet. Interiors, in press.

Forte, A. M. and J. X. Mitrovica. 1996. New inferences of mantle viscosity from joint inversion of long-wavelength mantle convection and postglacial rebound data. Geophys. Res. Lett, 23, $1147-1150$.

Fukao, T., M. Obayashi, H. Inoue, and M. Nenbai. 1992. Subducting slabs stagnant in the mantle transition zone. J. Geophys. Res, 97, 4809-4822.

Gable, C. W., R. J. O'Connell, and B. J. Travis. 1991. Convection in three dimensions with surface plates: Generation of toroidal flow. J. Geophys. Res, 96, 7205-7223.

Garnero, E. J. and D. V. Helmberger. 1996. Seismic detection of a thin laterally varying boundary layer at the base of the mantle beneath the central-Pacific. Geophys. Res. Lett, 23, 977-980.

Grand, S. P. 1994. Mantle shear structure beneath the Americas and surrounding oceans. J. Geophys. Res, 99, 11-621. 
Gurnis, M. 1989. A reassessment of the heat transport by variable viscosity convection with plates and lids. Geophys. Res. Lett, 16, 179-182.

Gurnis, M. and B. H. Hager. 1988. Controls on the structure of subducted slabs. Nature, 335, 317-322.

Hager, B. H. and R. W. Clayton. 1989. Constraints on the structure of mantle convection using seismic observations, flow models, and the geoid . Mantle Convection, R. W. Peltier. Gordon and Breach. New York. 657-763.

Hager, B. H. and R. J. O'Connell. 1981. A simple global model of plate dynamics and mantle convection. J. Geophys. Res, 84, 1031-1048.

Jacoby, W. R. and H. Schemling. 1982. On the effects of the lithosphere on mantle convection and evolution. Phys. Earth Planet. Inter, 29, 305-319.

Karato, S. and P. Wu. 1993. Rheology of the upper mantle: A synthesis. Science, 260, 771-778.

Kincaid, C. and P. Olson. 1987. An experimental study of subduction and slab migration. $J$. Geophys. Res, 92, 13-840.

King, S. D. and J. J. Ito. 1995. Effect of slab rheology on mass-transport across a phase-transition boundary. J. Geophys. Res, 100, 20-222.

King, S. D. and G. Masters. 1992. An inversion for radial viscosity structure using seismic tomography. Geophys. Res. Lett, 19, 1551-1554.

King, S. D. C. W. Gable, and S. A. Weinstein. 1992. Models of convection driven tectonic plates: A comparison of methods and results. Geophys. J. Int, 109, 481-487.

Puster, P., B. H. Hager, and T. H. Jordan. 1995. Mantle convection experiments with evolving plates. Geophys. Res. Lett, 22, 2223-2226.

Ricard, Y. and C. Vigny. 1989. Mantle dynamics with induced plate tectonics. J. Geophys. Res, 94, 17-559.

Seno, T. and S. Maruyama. 1984. Paleogeographic reconstruction and origin of the Philippine sea. Tectonophysics, 102, 53-84.

Sleep, N. H. 1990. Hotspots and mantle plumes: Some phenomenology. J. Geophys. Res, 95, $6715-6736$.

Tackley, P. J., D. J. Stevenson, G. A. Glatzmeir, and G. Schubert. 1993. Effects of an endothermic phase transition at $670 \mathrm{~km}$ depth on spherical mantle convection. Nature, 361, 137-160.

van der Hilst, R. D. 1995. Complex morphology of subducted lithosphere in the mantle beneath the Tonga trench. Nature, 374, 154-157.

van der Hilst, R. D., E. R. Engdahl, W. Spakman, and G. Nolet. 1991. Tomographic imaging of subducted slab under the island arcs of the northwest Pacific island arcs. Nature, 353, 3743.

van der Hilst, R. D. and T. Seno. 1993. Effects of relative plate motion on the deep structure and penetration depth of slabs below the Izu-Bonin and Mariana island arcs. Earth Planet. Sci. Lett, 120, 395-407.

van den Berg, A. P., P. E. van Keken, and D. A. Yuen. 1993. The effects of a composite nonNewtonian and Newtonian rheology on mantle convection. Geophys. J. Int, 115, 62-78.

Walcott, R. I. 1987. Geodetic strain and the deformational history of the North-island of New Zealand during the late Cainozoic. Philos. Trans. R. Soc. London, Ser. A, 321, 163-181.

Weinstein, S. A. 1996. Thermal convection in a cylindrical annulus with a non-Newtonian outer surface. Pure Appl. Geophys, 146, 551-572.

Weinstein, S. A. and P. Olson. 1992. Thermal convection with non-Newtonian plates. Geophys. J. Int, 111, 515-530.

Wysession, M. E., L. Bartko, and J. B. Wilson. 1994. Mapping the lowermost mantle using corereflected shear waves. J. Geophys. Res, 99, 13-684.

Yuen, D. A., O. P. Cadek, R. Boehler, J. Moser, and C. Matyska. 1994. Large cold anomalies in the deep mantle and mantle instability in the cretaceous. Terra Nova, 6, 238-245. 
Zhong, S. and M. Gurnis. 1994a. The role of plates and temperature-dependent viscosity in phase change dynamics. J. Geophys. Res, 99, 15-917.

Zhong, S. and M. Gurnis. 1994b. Controls on trench topography from dynamic models of subducted slabs. J. Geophys. Res, 99, 15-695.

Zhong, S. and M. Gurnis. 1995a. Mantle convection with plates and mobile, faulted plate margins. Science, 267, 838-843.

Zhong, S. and M. Gurnis. 1995b. Towards a realistic simulation of plate margins in mantle convection. Geophys. Res. Lett, 22, 981-984.

Zhong, S. and M. Gurnis. 1996. Interaction of weak faults and non-Newtonian rheology produces plate tectonics in a 3D model of mantle flow. Nature, 383, 245-247.

Zhou, H., D. L. Anderson, and R. W. Clayton. 1990. Modeling of residual spheres for subduction zone earthquakes, 1, Apparent slab penetration signatures in the NW Pacific caused by deep diffuse mantle anomalies. J. Geophys. Res, 95, 6799-6828.

Table 1. Physical and geometrical model parameters.

\begin{tabular}{lc}
\hline Parameter & Value \\
\hline Thickness of fluid layer, $D$ & $2.9 \times 10^{6} \mathrm{~m}$ \\
Outer radius, $R_{o}$ & $6.37 \times 10^{6} \mathrm{~m}$ \\
Temperature contrast, $T_{b}-T_{o}$ & $1600 \mathrm{~K}$ \\
Reference density, $\rho_{o}$ & $3.3 \times 10^{3} \mathrm{~kg} \mathrm{~m}^{-3}$ \\
Thermal conductivity & $3.0 \mathrm{~W} \mathrm{~m}^{-1} \mathrm{~K}^{-1}$ \\
Thermal diffusivity, $\kappa$ & $10^{-6} \mathrm{~m}^{-2} \mathrm{~s}^{-1}$ \\
Acceleration of gravity, $g$ & $10 \mathrm{~m} \mathrm{~s}^{-2}$ \\
Thermal expansion, $\alpha$ & $2.0 \times 10^{-5} \mathrm{~K}^{-1}$ \\
Average viscosity & \\
in the transition zone $(410-670 \mathrm{~km})$ & $4.0 \times 10^{21} \mathrm{~Pa} \mathrm{~s}$ \\
in the upper mantle $(120-410 \mathrm{~km})$ & $4.0 \times 10^{20} \mathrm{~Pa} \mathrm{~s}$ \\
in the oceanic lithosphere* $(0-120 \mathrm{~km})$ & $2.0 \times 10^{23} \mathrm{~Pa} \mathrm{~s}$ \\
Viscosity of the continent $(0-120 \mathrm{~km})$ & $2.0 \times 10^{25} \mathrm{~Pa} \mathrm{~s}$ \\
Equilibrium depth for endothermic phase change & $6.7 \times 10^{5} \mathrm{~m}$ \\
Equilibrium temperature for endothermic phase change & $1400 \mathrm{~K}$ \\
Clapeyron slope for the endothermic phase change & $3.5 \mathrm{MPa} \mathrm{K}-1$ \\
Density jumps across the phase change boundaries & $8.5 \%$ \\
Phase transition widths, $d$ & $3.2 \times 10^{4} \mathrm{~m}$ \\
$\left(\mu_{o}, c_{1}, c_{2}, n, \tau_{t}\right) \dagger$ & \\
the lower mantle & $\left(2 \eta_{r}, 3.0595,0.75647,1, \tau_{t}\right)$ \\
the transition zone & $\left(0.4 \eta_{r}, 3.0595,0.75647,1, \tau_{t}\right)$ \\
the upper mantle $\ddagger$ & $\left(0.02 \eta_{r}, 1.9187,-1.177,3, \tau_{t}\right)$ \\
the oceanic lithosphere & $\left(\eta_{r}, 1.9187,-1.177,3, \tau_{t}\right)$ \\
\hline
\end{tabular}

*For oceanic plates the cutoff for the maximum viscosity is $4.0 \times 10^{23} \mathrm{~Pa}$ s.

$\dagger$ Here $\tau_{t}$ is 2.5 bar; $\eta$, is reference viscosity and is $2.0 \times 10^{22} \mathrm{~Pa}$ s.

$\$$ Here $\mu_{o}$ for slabs within the upper mantle is equal to that for the oceanic plate $\eta_{r}$

Earth Interactions is published jointly by the American Meteorological Society, the American Geophysical Union, and the Association of American Geographers. Permission to use figures, tables, and brief excerpts from this journal in scientific and education works is hereby granted provided that the source is acknowledged. Any use of material in this journal that is determined to be "fair use" under Section 107 or that satisfies the conditions specified in Section 108 of the U.S. Copyright Law (17 USC, as revised by P.L. 94-553) does not require the publishers' permission. For permission for any other form of copying, contact one of the copublishing societies. 